\title{
BROOKHBVEN
}

NATIONAL LABORATORY

BNL-113871-2017-JA

\section{Building the Sun4Cast System: Improvements in Solar Power Forecasting}

Sue Ellen Haupt, Branko Kosović, Tara Jensen, Jeffrey K. Lazo, Jared A. Lee, Pedro A. Jiménez, James Cowie, Gerry Wiener, Tyler C. McCandless, Matthew Rogers, Steven Miller, Manajit Sangupta, Yu Xie, Laura Hinkelman, Paul Kalb, John Heiser

Accepted for publication in Bulletin of the American Meteorological Society

May 2017

Environmental \& Climate Science Dept.

Brookhaven National Laboratory

\section{U.S. Department of Energy \\ USDOE Office of Energy Efficiency and Renewable Energy (EERE), Solar Energy Technologies Office (EE-4S)}




\section{DISCLAIMER}

This report was prepared as an account of work sponsored by an agency of the United States Government. Neither the United States Government nor any agency thereof, nor any of their employees, nor any of their contractors, subcontractors, or their employees, makes any warranty, express or implied, or assumes any legal liability or responsibility for the accuracy, completeness, or any third party's use or the results of such use of any information, apparatus, product, or process disclosed, or represents that its use would not infringe privately owned rights. Reference herein to any specific commercial product, process, or service by trade name, trademark, manufacturer, or otherwise, does not necessarily constitute or imply its endorsement, recommendation, or favoring by the United States Government or any agency thereof or its contractors or subcontractors. The views and opinions of authors expressed herein do not necessarily state or reflect those of the United States Government or any agency thereof. 


\section{Building the Sun4Cast System: Improvements in Solar Power Forecasting}

Sue Ellen Haupt ${ }^{1}$, Branko Kosović ${ }^{1}$, Tara Jensen ${ }^{1}$, Jeffrey K. Lazo ${ }^{1}$, Jared A. Lee ${ }^{1}$,

Pedro A. Jiménez ${ }^{1}$, James Cowie ${ }^{1}$, Gerry Wiener ${ }^{1}$, Tyler C. McCandless ${ }^{1,6}$, Matthew Rogers ${ }^{2}$, Steven Miller ${ }^{2}$, Manajit Sangupta ${ }^{3}$, Yu Xie $^{3}$, Laura Hinkelman ${ }^{4}$, Paul Kalb ${ }^{5}$, John Heiser ${ }^{5}$

\footnotetext{
${ }^{1}$ Research Applications Laboratory, National Center for Atmospheric Research, Boulder, CO

${ }^{2}$ Cooperative Institute for Research of the Atmosphere, Colorado State University, Fort Collins, $\mathrm{CO}$

${ }^{3}$ National Renewable Energy Laboratory, Golden, CO

${ }^{4}$ University of Washington, Seattle, WA

${ }^{5}$ Brookhaven National Laboratory, Upton, NY

${ }^{6}$ Current Affiliation: Ascend Analytics, Boulder, CO
}

Corresponding Author: $\quad$ Sue Ellen Haupt

National Center for Atmospheric Research

P.O. Box 3000

Boulder, CO 80301

Tel: 303-497-2763

Email: haupt@ucar.edu

Submitted to Bulletin of the American Meteorological Society

January 2017

Revised May 2017 


\section{Abstract}

2

3 As integration of solar power into the national electric grid rapidly increases, it becomes

4 imperative to improve forecasting of this highly variable renewable resource. Thus, a team of

5 researchers from public, private, and academic sectors partnered to develop and assess a new

6 solar power forecasting system, Sun4Cast ${ }^{\circledR}$. The partnership focused on improving decision-

7 making for utilities and independent system operators, ultimately resulting in improved grid

8 stability and cost savings for consumers. The project followed a value chain approach to

9 determine key research and technology needs to reach desired results.

11 Sun4Cast integrates various forecasting technologies across a spectrum of temporal and spatial

12 scales to predict surface solar irradiance. Anchoring the system is WRF-Solar ${ }^{\circledR}$, a version of the

13 Weather Research and Forecasting (WRF) numerical weather prediction (NWP) model

14 optimized for solar irradiance prediction. Forecasts from multiple NWP models are blended via

15 the Dynamic Integrated Forecast (DICast ${ }^{\circledR}$ ) System, the basis of the system beyond about $6 \mathrm{~h}$.

16 For short-range (0-6 h) forecasts, Sun4Cast leverages several observation-based nowcasting

17 technologies. These technologies are blended via the Nowcasting Expert System Integrator

18 (NESI). The NESI and DICast systems are subsequently blended to produce short to mid-term

19 irradiance forecasts for solar array locations. The irradiance forecasts are translated into power

20 with uncertainties quantified using an analog ensemble approach, and are provided to the

21 industry partners for real-time decision-making. The Sun4Cast system ran operationally

22 throughout 2015 and results were assessed.

24 This paper analyzes the collaborative design process, discusses the project results, and provides recommendations for best-practice solar forecasting. 


\section{Capsule:}

29

30 The Sun4Cast System results from a research-to-operations project built on a value chain

31 approach, and benefiting electric utilities' customers, society, and the environment by improving

32 state-of-the-science solar power forecasting capabilities. 
 \\ Introduction}

35 This paper reports on the results of a public-private-academic collaboration to improve the stateof-the-science of solar power forecasting. Led by the National Center for Atmospheric Research (NCAR), the project applied a value chain approach to leverage the vision of the team members and progress towards the end goal of improving the economics of deploying solar energy (Haupt et al. 2016). This paper analyzes the collaborative design process, discusses the project results, and provides recommendations for "best-practice" solar forecasting.

\section{Background}

The use of solar power is increasing exponentially. In the U.S., solar power has grown from 1.2 GW ( $0.1 \%$ of the electricity supply) in 2011 to more than $30 \mathrm{GW}$ in 2016 , largely due to the rapid decreases in the levelized cost of solar electricity production ( $\mathrm{LCOE}^{1}$; Woodhouse et al. 2016). It is expected to continue to grow at similar rates for the foreseeable future. On a global basis, the International Energy Agency states that "Renewable energy will represent the largest single source of electricity growth over the next five years, driven by falling costs and aggressive expansion in emerging economies ... renewables hold [great promise] for affordably mitigating climate change and enhancing energy security."2

Harvesting solar power relies on transforming the sun's energy in the form of irradiance into usable power. However, some of this energy is attenuated by atmospheric aerosols and clouds on its way to the earth's surface, decreasing the available irradiance depending on the atmospheric conditions. The variability of the available solar power becomes an important consideration for utilities as they maintain grid stability and plan for the following day's unit allocations.

Thus, as integration of solar power into the national electric grid rapidly increases, it becomes increasingly imperative to overcome the traditional forecasting challenges of this highly variable

\footnotetext{
${ }^{1}$ LCOE accounts for the total lifecycle cost of energy from project inception through decommissioning, including electricity generation.

${ }^{2}$ https://www.iea.org/newsroom/news/2015/october/renewables-to-lead-world-power-market-growth-to-2020.html, accessed 8 Dec 2016.
} 
renewable resource. Solar power prediction is accomplished by different techniques for various time scales. Solar energy is particularly variable over space and time because of the myriad complexities caused by the dynamic evolution of clouds.

\section{Variability of Solar Power}

The variability of power output is greater with high penetrations of solar on the grid than with high penetrations of wind (Lew et al. 2012), illustrating a key challenge of solar power integration. A utility company's operating reserve requirements, which provide for rapid changes in matching system electric load, are determined by the response speed (ramp rate and start-up time), response duration, frequency of use (continuously or only during rare events), direction of change (up or down), and type of control mechanism (Ela et al. 2013). Traditionally, utilities have had to increase the amount of operating reserves to account for the variability of renewable energy. More recently, however, these operating reserves are being appropriately managed with accurate solar forecasts, as energy costs can be strategically minimized with knowledge of the short- and long-term variations in solar irradiance (Curtright and Apt 2008).

The quantification of temporal solar irradiance variability caused by the dynamic evolution of clouds has been extensively studied. Hinkelman et al. $(2013,2014)$ determined that cloud optical depth and cloud height are the best predictors of irradiance variability at one-minute time resolution. Gueymard and Wilcox (2011) analyzed the regional dependence of solar power and showed that greater variability tends to occur in coastal and mountainous areas, such as the California coast, due to topography-induced micro-climates.

The difficulties in predicting cloud cover at specific locations and times are well known, and a number of groups around the world are actively engaged in solar power forecasting research. Real-time solar power forecasting is reviewed in recent publications, including Kleissl (2013), Troccoli et al. (2014), Dubus (2014), and Tuohy et al. (2015). Lorenz et al. (2014) reviews the extensive work of the team at the University of Oldenburg in Germany. The Australian initiative is ongoing (Davy and Troccoli 2012). Schroedter-Homscheidt et al. (2013) point out the need for 
91 improved aerosol prediction for solar power prediction and discuss techniques leveraging

92 ECMWF chemistry forecasts.

93

\section{The Sun4Cast Project}

This project was selected for funding by the DOE's SunShot Initiative as a "Public-PrivateAcademic Partnership to Advance Solar Power Forecasting”. The goals of this project were to:

- Build a solar power forecasting system to advance the state-of-the-science through cutting-edge research;

- Test the system with appropriate metrics for several geographically diverse, highpenetration solar utilities and independent system operators (ISOs); and

- Disseminate the research results widely to raise the bar on solar power forecasting technology.

\section{Project Progression}

\section{Beginning with the End in Mind}

The first step of any project is assembling the right team to accomplish the goals, including identifying and engaging the stakeholders. Here, the end users are the electric utilities and system operators who make the decisions on unit allocation, energy trading, and real-time integration into the grid. Several utilities and ISOs were part of the process from the beginning and some others participated during portions of the project. It was important for the researchers to listen to their needs in planning the details of the system, how to bring it together, how to convey the output, and how to properly assess it to best help these end users. A second set of stakeholders is the commercial forecast providers who regularly communicate and transfer forecast results to the end users. 
The scientists who performed the research and the software engineers who configured and built the system came from national laboratories and universities that perform use-inspired research. The NCAR-led team was already immersed in solar forecasting research at the time of the award.

The first-year project workshop at NCAR was an opportunity to convene the entire team to think through how to integrate all of the research into a working Sun4Cast system. The workshop emphasized meeting the needs of the users. After an initial introduction to the project goals, the workshop commenced with a user panel of utility and ISO representatives to explain how they use forecasts and what they need in the forecast, as well as when it must be delivered to be most useful. We saw this session as "beginning with the end in mind" as a way to envision the project outcome. This began the process of conceptual modeling (see sidebar), which brought out ideas from the various stakeholders, and that the management team then synthesized into a working value chain (Figure 1) that could guide the rest of the project. This approach, derived from social science, is rather novel for configuring and running scientific projects, but proved to be quite effective for this large integrated project.

\section{Metrics from the Start}

Another unique feature of this project is the development of metrics across SunShot teams through listening to stakeholder needs. Development of metrics was accomplished jointly with a collaborative team that included DOE SunShot Initiative leadership, the IBM Watt-Sun forecasting team (Utsler 2014), and NOAA team members, in addition to the Sun4Cast team. That group held several workshops that engaged end users. With that input and many team teleconferences, the group designed a table of proposed metrics (Table 1) for evaluating the system (Zhang et al. 2014; Jensen et al. 2016). In parallel, the NCAR Metrics team worked with our utility stakeholders and discussed methods to assess value provided by improved forecasting.

\section{The Sun4Cast System}

The Sun4Cast ${ }^{\circledR}$ system (Figure 2) has two main forecast tracks: a Nowcast track that forecasts at high temporal resolution extending to $6 \mathrm{~h}$, the results of which are blended via the Nowcasting 
Expert System Integrator (NESI), and the Dynamic Integrated ForeCast (DICast ${ }^{\circledR}$; Mahoney et al. 2012; Myers et al. 2011) track that forecasts at coarser temporal resolution out to several days based on numerical weather prediction (NWP). Both NESI and DICast apply a consensus forecasting approach, meaning that they blend and optimize multiple models to provide a better forecast than any of the models would produce alone. That is, they consider multiple input forecasts and weight those forecasts according to the recent observed skill of each input.

While this consensus forecasting approach has been applied to forecasting more common weather variables (e.g., air temperature), it had not previously been applied to solar irradiance forecasting in any significant way. Only recently have public forecast systems begun to use a consensus forecast approach, such as in the NOAA National Blend of Models (Gilbert et al. 2016). In the private sector, some companies employ a consensus approach, while others rely on a single-source model; much of this is proprietary.

Forecasts from Sun4Cast are provided every $15 \mathrm{~min}$, extend to $72 \mathrm{~h}$, and can be provided as far out as $168 \mathrm{~h}$.

\section{WRF-Solar - Improving NWP for Irradiance Forecasting}

Most modern weather forecasting systems rely on NWP models for their base forecasts. Thus, a major emphasis of this project was to improve NWP by developing, testing, evaluating, and improving WRF-Solar@, the first NWP model specifically designed to meet the increasing demand for specialized forecast products for solar energy applications (Jiménez et al. 2016a,b). WRF-Solar is used in both the NESI and DICast systems.

An intercomparison of different global, multiscale, and mesoscale models' skill in forecasting solar irradiance performed by Perez et al. (2013) indicated that the ECMWF global model significantly outperforms the GFS-driven WRF model over a wide range of sites. So far, this has been interpreted as partially due to shortcomings in cloud modeling and data assimilation. It is also possible that the radiative transfer algorithms in the U.S. forecast models do not perform as well for this application. This hypothesis was confirmed by Ruiz-Arias et al. (2013) in the case of the WRF model (Skamarock et al. 2008). That study highlighted biases in one frequently used radiation algorithm in WRF, and the need for improvement by adding aerosol data. In addition, 
177 cloud formation and dissipation needed to be improved. Thus, the project team made a variety of 178 augmentations to the WRF model to tailor it for solar power forecasting. Figure 3 depicts these 179 WRF-Solar upgrades.

180 The first augmentation focused on improving the solar tracking algorithm to account for 181 deviations associated with the eccentricity of the Earth's orbit and obliquity. Because solar 182 energy applications require more frequent calls to the radiation package, inaccuracies in the solar 183 position caused a non-negligible error.

184 Second, WRF-Solar added the direct normal irradiance (DNI) and diffuse (DIF) components 185 from the radiation parameterization to the model output in addition to global horizontal 186 irradiance (GHI), parameterizing them when needed (Ruiz-Arias et al. 2010).

187 Third, efficient parameterizations were implemented to either interpolate the irradiance in 188 between calls to the radiative transfer parameterization, or to use a fast radiative transfer code 189 that avoids computing three-dimensional heating rates but provides the surface irradiance (Xie et 190 al. 2016).

191 Fourth, a new parameterization was developed to improve the representation of absorption and 192 scattering of radiation by aerosols (aerosol direct effect), including allowing high spatio-temporal 193 variability of aerosols. The treatment of aerosols (Ruiz-Arias et al. 2014) allows for the ingestion 194 of aerosol optical properties with time stamps to accurately model the temporal variations in 195 aerosol loading, permitting the ingested aerosol concentration to represent the aerosol optical 196 properties in WRF-Solar. Jimenez et al. (2016a) examined the use of several different aerosol 197 data and found improvement with dynamic input.

198 A fifth advance was to specify interactions of the aerosols with the cloud microphysics, altering 199 the cloud evolution and radiative properties (aerosol indirect effects). Traditionally, these effects 200 have only been implemented in atmospheric chemistry models, which are significantly more 201 computationally expensive than NWP models without detailed chemistry. WRF-Solar uses a 202 simplified treatment of the aerosols (i.e., only two general aerosol species are allowed, 203 specifically the nonhygroscopic ice-nucleating aerosols which are dust particles and the 204 hygroscopic aerosols including sea salts, organic matter, and sulfates) that accounts for changes 
in the size of cloud hydrometeors to represent these aerosol indirect effects (Thompson and Eidhammer 2014) with moderate increase in computational cost $(\sim 16 \%)$. The aerosols are advected by the model dynamics and the parameterization is linked to the WRF-Solar aerosol parameterization to provide a fully coupled representation of the cloud-aerosol-radiation system.

A sixth development accounts for the feedbacks that sub-grid scale clouds produce in shortwave irradiance as implemented in a shallow cumulus parameterization (Deng et al. 2003, 2014). The scheme includes predictive equations for the sub-grid-scale cloud water/ice content and the cloud fraction.

Finally, as described below, WRF-Solar was coupled with elements of a forefront satellite data assimilation model, which allows assimilation of infrared irradiances from satellites, resulting in an improved initialization of the cloud field that further increases the performance of short-range forecasts.

Penn State University and the National Renewable Energy Laboratory (NREL) collaborated with NCAR in making these enhancements. NCAR responded to numerous requests to use beta versions of WRF-Solar. The community sees it as a way to advance deployment of solar energy by enabling better forecasting of the irradiance resource. NCAR expects to further exercise and improve WRF-Solar in future projects.

\section{Nowcasting Systems}

The shortest ranges of forecasts must leverage measurements that are available in real time, those from both ground-based sensors as well as satellite-mounted sensors. The shortest range irradiance forecast $(0-6 \mathrm{~h})$ is supplied by the NESI system. The NESI system consists of several short-range forecasting systems: the Total Sky Imager Nowcast (TSICast; Peng et al. 2015), StatCast (McCandless et al. 2015, 2016a,b), the Cooperative Institute for Research in the Atmosphere (CIRA) nowCast (CIRACast; Miller et al. 2012; Rogers et al. 2015), the Multisensor Advection-Diffusion nowCast (MADCast; Auligné 2014a,b; Descombes et al. 2014), WRF-Solar-Now, and MAD-WRF.

TSICast is a ground-based cloud imaging and tracking system that operates on the shortest time scale, with a latency of only a few minutes and forecasts that currently extend to approximately 
$15 \mathrm{~min}$. This project facilitated research to develop and test model algorithms and improve the hardware and software so that new high definition cameras deployed at multiple nearby locations facilitate discernment of clouds at varying levels and advection according to the winds observed at those levels (Peng et al. 2015).

Pyranometers supply the in situ data for initializing StatCast. During the course of this project, short-range statistical forecasting was advanced by emphasizing regime-dependent forecasting, both implicitly through a regression tree approach, and more explicitly by combining clustering techniques with artificial neural networks. These methods make a substantial improvement in MAE (from 15-50\%) over short-range smart persistence forecasts (McCandless et al. 2015, 2016a,b). While multiple versions of StatCast were developed, in this article we focus on StatCast-Cubist (McCandless et al. 2015), which uses a hierarchical regression tree (the Cubist model; Quinlan 1992; Kuhn et al. 2012).

A second category of systems employs satellite imagery and uses that information to discern clouds and their motion, allowing the systems to project the clouds, and the resulting irradiance attenuation, in time. During this project, NOAA reduced satellite data latency while allowing the recovery of higher resolution data. The CIRA team advanced cloud shadowing, parallax removal, and implementation of better advecting winds at different altitudes (Rogers et al. 2015). A second satellite-based system, MADCast, assimilates data from multiple satellite imagers and profilers to incorporate a cloud fraction for each grid column into the dynamic core of WRF (Auligné 2014a,b; Descombes et al. 2014). That model allows advection of the clouds directly via the WRF dynamics.

One issue with the satellite data assimilation methods described above is that they do not allow for cloud formation and dissipation, which is in the domain of NWP models. Thus, WRF-Solar (Jiménez et al. 2016a,b) was adapted for nowcasting, being run at lower resolution more frequently to fill the gap of time (between 1 and 6 hours) where changes in the clouds are most likely (WRF-Solar-Now). Finally, as the project progressed, it became obvious that combining the advantages of WRF-Solar-Now with MADCast, which assimilates the current cloud observations and allows for cloud formation and dissipation via WRF-Solar-Now. Thus was born MAD-WRF (Haupt et al. 2016). 
The Nowcasting system evaluation (Haupt et al. 2016) revealed that each component has a "sweet spot" where it is most effective. For instance, the satellite-based method, CIRACast, provides the best initial state during partly cloudy conditions, although that may not carry through to clear or fully cloudy conditions. It does, however, provide value for forecasting shortrange ramps due to changing cloud cover (Figure 5-8 of Haupt et al. 2016). Thus the blending of the different nowcasting components produces an effective method of nowcasting.

\section{System Engineering - Integration}

Building the individual component models is necessary, but not sufficient, to supplying a highquality solar power forecast. It is also critical to engineer a system that smoothly handles data input and output and effectively blends the results of each of the components. This engineered system must allow for missing observations or model results as well as allowing for "graceful degradation" when not all systems are performing optimally. Haupt and Kosović (2016) discuss the "big data" aspects of this system and how it brings observational data together with model data to produce a complete system.

NESI uses recent performance information to smartly blend the Nowcast components by weighting the model contributions according to their historical performance at each lead time. Although this is currently accomplished using historical statistics, moving to a dynamically blended system in the future could prove advantageous.

The DICast system blends the output of NWP models, both WRF-Solar output as well as that from publicly available models, including NOAA's High Resolution Rapid Refresh (HRRR), North American Model (NAM), Global Forecast System (GFS), and the Canadian Global Environmental Multiscale Model (GEM) for this project. This blending is accomplished by first correcting biases in the individual models, then by dynamically optimizing their weights for each lead time. Although DICast has shown a high degree of accuracy for other forecast variables (Myers et al. 2011), this project was the first time that it was employed for irradiance forecasts. Development during the project included building algorithms to account for disparate model time frames and consideration of solar angle in blending the model output correctly. The DICast and Nowcast systems must in turn be blended during the overlap periods. 
At this point, the blended system forecasts irradiance; thus, it is then necessary to convert irradiance to power. This was accomplished by using a Cubist regression tree model (Kuhn et al. 2012) that was trained on historical irradiance and power observations. The advantage of this empirical approach to power conversion is that it can use GHI, DNI, or plane-of-array (POA) irradiance as long as these are used consistently. Furthermore, it can implicitly account for the specifics of solar panel installation (tilt angle, etc.) by training the power output directly to the observed input solar irradiance. This process inherently mitigates problems by not directly using any metadata, which is often inaccurate.

The last step in the forecast process applies the analog ensemble technique (AnEn; Delle Monache et al. 2011, 2013; Alessandrini et al. 2015, Haupt et al. 2016). The AnEn searches the database for past forecasts most similar to the current forecast. It then forms a probability density function (pdf) of the observations that correspond to those historical forecasts. The mean of this pdf becomes the improved forecast and its spread quantifies the uncertainty. Thus, the AnEn both corrects the power forecast and provides probabilistic information to quantify the uncertainty of the forecast. Again, this project was a first opportunity to exercise AnEn for solar power and it effectively quantified the uncertainty in the solar power forecasts with significantly lower computational cost than standard multi- simulation model ensembles.

\section{Testing and Evaluating the System}

\section{Quasi-Operationalization}

The system was deployed in concert with the team partners as forecast systems came online. The full system was run in quasi-operational mode from January 2015 through March 2016. The partners in the project are located in a geographically diverse set of locations across the country the eastern U.S. [Brookhaven National Laboratory (BNL)], central U.S. (Xcel Energy), and western U.S. [Sacramento Municipal Utility District (SMUD) and Southern California Edison (SCE)] - thus bolstering the robustness of the results.

\section{Assessment}

The verification system is based on NCAR's Model Evaluation Tools (MET;

http://www.dtcenter.org/met/users/) package, specifically the Stat-Analysis tool to compute 
verification measures of irradiance and power and the METViewer database and display system to aggregate the results. Several baselines are available for this evaluation, including persistence with knowledge of sky condition and solar zenith angle (labeled "Smart Persistence") for Nowcast components and publicly available NWP models for both the Nowcast and DICast components. Here we show a small sample of the results reported elsewhere (Haupt et al. 2016).

Day-Ahead Assessment

DICast statistically blends NWP forecasts for the Sun4Cast system, providing the forecast beyond $6 \mathrm{~h}$ (although it also produces forecasts from time $\mathrm{t}=0$ ). Figure 4 indicates that when scores are aggregated over all partners' locations, including BNL, Xcel, SMUD, and SCE, the blended Sun4Cast and WRF-Solar systems perform better than the operational models for dayahead forecasts. Statistical analysis through pairwise differences and bootstrapped confidence intervals indicates that these results are statistically significant at the $95 \%$ level for all issue times when NAM is compared to DICast, and all but the first issue time when NAM is compared to WRF-Solar. Figure 5-13 in Haupt et al. (2016) also indicates statistically significant results at all lead times.

\section{Nowcast Assessment}

One purpose of exploring multiple nowcast components is that each one is potentially skillful for a different forecast horizon (lead time) and sky condition. Figure 5 provides a measure of each model's skill when these scores are accumulated over the geographic regions for the entire 15month evaluation period. The scores were aggregated over the hourly initialization times. It also shows the skill for clear, partly cloudy, and cloudy conditions. During clear conditions, only WRF-Solar-Now and the blended nowcast NESI outperform Smart Persistence to 45 minutes (0.75 hours). After this, all methods have lower MAE than Smart Persistence, with WRF-SolarNow and CIRACast performing the best out through $2 \mathrm{~h}$ and WRF-Solar-Now and MAD-WRF through 3-6-h lead times. For partly cloudy and cloudy conditions, the performance of the components is much more variable, with NESI and MADCast providing the best forecasts during partly cloudy conditions and StatCast-Cubist and MAD-WRF giving the better forecasts during cloudy conditions. One can see oscillations in the blended models such as MAD-WRF and NESI as they switch weighting from one model to another. 
To better understand the performance of the various Nowcast components in specific situations, a series of inter-comparison case studies was undertaken by Lee et al. (2017). Fifteen-minute average GHI predictions were compared against observations from seven pyranometers near

352 Sacramento, California, that are owned and operated by SMUD. The GHI forecasts from several 353 forecast models - StatCast-Cubist, CIRACast, MADCast, and four versions of WRF-Solar 354 were compared over four case days with canonical sky cover regimes (i.e., clear skies, morning stratocumulus, mix of clouds and sun, and overcast).

356 Statistical forecasting with StatCast-Cubist provided the best forecast under clear skies, due to the 357 attenuation from typical aerosol loading already accounted for in its training dataset and the 358 observations. StatCast typically had some of the lowest errors on all case days for the first 45-60 359 min. GHI forecast errors for longer lead times increased when clouds were present, however. 360 Especially in cases when rapidly changing cloud cover led to reversing trends in GHI, this result 361 is unsurprising.

362 The satellite-based forecasting methods CIRACast and MADCast also generally performed well 363 at short lead times. Unsurprisingly, these methods struggled on days with rapid formation, growth, 364 and decay of clouds after forecast initialization. Cloud fields predicted by MADCast are generally 365 smoother than those from CIRACast, but the GHI variability is often grossly underestimated by 366 MADCast.

367 NWP with WRF-Solar performed comparatively accurately for GHI predictions for all four cases. 368 The best accuracy resulted when representing the aerosol direct effect using a high-resolution 369 aerosol dataset and when representing the radiative effects of unresolved shallow cumulus clouds 370 using the Deng et al. (2014) mass-flux scheme. Improving the treatment of aerosols made a 371 noticeable difference in clear sky conditions, while the shallow cumulus scheme substantially 372 reduced GHI forecast errors during periods of extensive cloud cover. 
375 When the output of the power conversion module is compared to measured power for five solar 376 farms, mean absolute errors normalized to percentage of capacity (MAPE) range from 1.3 to $4.4 \%$ 377 with a median value of $2.1 \%$. as discussed in more detail in Haupt et al. (2016).

378

379

380

381

382

383

384

385

386

387

388

389

390

391

392

393

394

395

396

397

398

399

400

401

402

403

404

The AnEn showed promising results for providing an ensemble mean forecast and uncertainty quantification for GHI forecasts. Toward the end of the project, the technique was also applied to power forecasts for SMUD locations. The RMSE of the AnEn mean and Sun4Cast versus power measurements were assessed for the 0-72 $\mathrm{h}$ forecast. Overall, AnEn provides substantial improvement to the deterministic forecast as measured by root mean squared error (RMSE), mean absolute error (MAE), and bias error. Improvements in power forecasts are similar to those reported for GHI forecasts with a median improvement of 17\% in RMSE.

Probabilistic forecasts were also computed for 10, 25, 50, 75, and 90\% exceedance of power capacity. A marked improvement was obvious in terms of Brier Skill Score (Wilks 2011) for probabilities of an exceedance of $50 \%$ of capacity (Haupt et al. 2016). The computed Brier Skill Score across all lead times was 0.55 (Figure 5-23 of Haupt et al. 2016).

\section{Economic valuation}

Production cost modeling (PCM) approaches were used to assess the value of energy forecasts. PCM is used by utilities on an operational basis to determine the optimal system configuration (e.g., lowest cost) for the day-ahead time frame, given expected demand (load) while taking into consideration all other relevant factors (e.g., fuel costs, maintenance on facilities, transmission constraints, etc.). Martinez-Anido et al. (2016) used a PCM to derive value estimates for dayahead solar power forecasting improvements for the New England Independent System Operator (ISO-NE) with varying solar power penetrations $(4.5 \%, 9.0 \%, 13.5 \%$, and $18.0 \%)$ and solar power forecasting improvements $(25 \%, 50 \%, 75 \%$, and $100 \%)$. Their analysis indicates that improved solar power forecasting reduces operational electricity generation costs. The benefits increase further with higher penetration levels and with larger forecast improvements. 
An economic evaluation based on PCM for the Public Service Company of Colorado showed that a 50\% improvement (see Figure 5-5 of Haupt et al. 2016, which indicates a 45-48\% improvement over a year of the project) in day-ahead forecast accuracy will save their customers $\$ 819,200$ in 2024 with the projected solar deployment for that year. Using econometrics, NCAR scaled this savings to a national level and showed that an annual expected savings for this $50 \%$ forecast error reduction ranges from $\$ 11 \mathrm{M}$ in 2015 to $\$ 43 \mathrm{M}$ expected in 2040 with increased solar deployment (Lazo et al. 2017b). This amounts to \$455M in potential discounted savings over the 26-year period of analysis (Haupt et al. 2016).

\section{Discussion}

The DOE-funded Public-Private-Academic Partnership to Advance Solar Power Forecasting project functioned as a collaborative team, with each participant contributing to portions of the Sun4Cast ${ }^{\circledR}$ Solar Power Forecasting System. The project began by seeking to understand industry needs in order to configure a system that meets those needs, based on characterizing the problems using a value chain approach. The end result is the Sun4Cast solar power forecasting system that has been thoroughly evaluated.

\section{Recommendations for best practice forecasting}

A major goal of this project was to draw conclusions about the performance of each component system and make recommendations for best practices in configuring solar power forecasting systems. Some specific recommendations include the following:

- Blend component models or systems together. The forecast from blended models/systems is invariably significantly better than those produced by a single model or approach, when evaluating the full timeframe.

- Use an NWP model tuned for the purpose. Using WRF-Solar® significantly improved forecasting. Including high-resolution, high quality aerosol datasets and a shallow cumulus scheme have proven especially beneficial.

- Include multiple NWP models. Blending multiple NWP models improves the forecast for time scales from $3 \mathrm{~h}$ through the day-ahead forecast and beyond. 
- Employ statistical learning methods trained on targeted in situ observations for short-range forecasting. StatCast trained using local pyranometer data was better than smart persistence, even at short time scales (15 min to $3 \mathrm{~h}$ ), and TSICast, which uses multiple sky imagers as well as statistical learning techniques, improved upon persistence for time ranges less than $15 \mathrm{~min}$.

- Use satellite-based cloud advection, being mindful of its challenges. For mountainous or coastal regions, it is necessary to include some model physics to account for stationary clouds as well as for cloud formation and dissipation. It is important to include the improvements related to correcting for shadowing and parallax as accomplished by CIRACast.

- Combine NWP with satellite data via assimilation for nowcasting. MAD-WRF runs quickly and produced the best forecast on the 1-6-h time scale.

- Include analog ensembles. The AnEn both improves upon the deterministic blended forecast and produces a probabilistic prediction that is well calibrated.

- Develop an empirical power conversion method. Such methods are amenable to training using site-specific information, even when missing metadata. Artificial intelligence techniques are capable of predicting directly from an observation to a target value if historic training data are available.

- Perform verification with an enhanced series of metrics. Carefully chosen metrics allow for meaningful evaluation and tuning of both individual models and the entire system.

- Consider economic metrics of value to the user. Expand the use of PCM and reserves analysis to quantify and demonstrate the economic benefits of improvements to solar power forecasting.

Typical of any real-world applied project, the team encountered several challenges. Chief among these issues was solar farm data availability and quality, which is a critical issue for any forecasting system. Addressing these issues would benefit researchers, practitioners, and the end users, but would require some coordination or adoption of standards across the community. 
Additionally, historical data were often unavailable. Statistical learning and artificial intelligence methods require historical data for training the system, so where data do not exist, those techniques cannot be employed. Finally, because the atmosphere is a chaotic dynamical system, there are limits to predictability that should be recognized in designing and assessing any forecast system. Although weather and climate forecasting is constantly improving, the sensitivity to initial conditions provides a theoretical limit on how well we can forecast for a particular timeframe.

\section{Leveraging the Design Process}

The team demonstrated and evaluated a working Sun4Cast solar power prediction system that includes the multiple components described herein. The individual components and the overall Sun4Cast system were validated using the metrics developed toward the beginning of the project. The team met or exceeded most of the target values specified by the project sponsor, the DOE SunShot Initiative. Data streams from various model systems were made available to the forecasting partners, forecasts were regularly provided to the utility and ISO partners, and feedback from the partners was used to iteratively improve the forecasting models.

The team conducted transformative research in statistical forecasting, advective/dynamic shortrange forecasting, nowcasting with real-time data assimilation, satellite techniques and data assimilation for solar forecasting, NWP with the WRF-Solar model (including cloud physics parameterization, convective parameterization, clear-sky aerosol estimation, and radiative transfer modeling), irradiance-to-power conversion, and uncertainty quantification.

The team approach of infusing social science from the beginning to facilitate team building was widely successful. We believe that this approach of starting with the end in mind, listening to the end user, group mental modeling exercises, and continued communication throughout a project can be leveraged for other large projects with many interacting parts.

\section{Continuity and Next Steps}

The team members have all grown in their research capabilities in solar energy and the collaborative research is expected to continue. Further improvements can be made and new 
491 applications of solar power as well as forecasting its output are continually appearing. A direct

492 point of continuity is continued collaboration among the partners.

493

494 The details of the models are documented in Haupt et al. (2016) and individual journal papers

495 describing each model, many of which are referenced herein. Many of the component models are

496 OpenSource and available from NCAR (see

497 https://wiki.ucar.edu/display/Sun4Cast/Sun4Cast+Home).

498

499 Our utility and ISO partners provided feedback regarding their vision of the future of solar power

500 forecasting. One partner commented, “...the industry need is still there and it will only get larger

501 as more distributed energy is connected to the grid." Another said that forecasts will be from

502 "centralized regional transmission authority (RTO)/ISO/balancing authority (BA)-generated

503 forecasts that will have multiple uses and at varying granularities." As a community we must

504 strive to continually provide improved forecasts in a form that will be appealing and beneficial to 505 end users.

506

507 As the penetration of solar power continues to grow, solar power forecasting with systems such

508 as Sun4Cast will provide key technologies that will make the economics more feasible, thus

509 empowering greater solar power deployment. Such enhanced deployment has the potential to

510 improve air quality, mitigate climate change, improve energy security, and provide enhanced

511 employment opportunities throughout the renewable energy sector.

512

\section{Acknowledgements}

514

515

516

517

518

519

520

521
This work was primarily funded by the U.S. Department of Energy's SunShot Initiative under award DE-EE0006016, with additional funding provided by the National Science Foundation. We thank the many team members, including those from Penn State University, University of Hawaii, Solar Consulting Services, Global Weather Corporation, Schneider Electric, Atmospheric and Environmental Research, MDA Information Systems, Sacramento Municipal Utility District, Xcel Energy Systems, New York Power Authority, Long Island Power Authority, Hawaiian Electric Company, New York State Department of Economic Development, 
522 Sothern California Edison, California Independent System Operators, New York Independent 523 System Operators, University of Buffalo, and Army Research Laboratory/White Sands.

524 Computing resources for the MADCast and WRF-Solar runs were provided on NCAR's

525 Yellowstone computing system (http://n2t.net/ark:/85065/d7wd3xhc), which is operated by

526 NCAR's Computational and Information Services Laboratory and sponsored by the National

527 Science Foundation. 


\section{Conceptual Modeling}

532 With the background provided by the stakeholders, time was devoted during the first-year project 533 workshop to developing a shared conceptual model of the weather-solar-power value chain. The 534 group broke into five pre-assigned teams that mixed forecast users, providers, and researchers to develop mental models of the forecast value chain. The objectives of this exercise were team

536 building, facilitating discussion, enhancing understanding across all participants in the project,

537 building a qualitative model of the weather-solar value chain, and explaining how research to 538 improve forecasts will create value (Lazo 2017a).

All team members were given general guidance to spend time "drawing" and discussing their own value chain, considering issues such as: What values, decisions, or outcomes do you think are important to end users and decision-makers? How does weather impact those decisions? How does weather information relate to those decisions? How would changes or improvements in weather forecasts change those outcomes? Who are the decision-makers? What are their needs, resources, and constraints? How do different "agents" in the value chain add value to information? What is the relevant forecast information? What if this project improved the relevant forecast by $\mathrm{x} \%$ ? What does an $\mathrm{x} \%$ improvement mean? How does an $\mathrm{x} \%$ improvement affect outcomes for weather forecast vendors, utilities, ISOs, and regional transmission operators (RTOs)? This approach was quite successful for team building and enabled the group to come to a joint visualization of the project goals.

The team then delved deeper into the elements of the forecasting systems and determined how to fit them into one cohesive whole. Figure 1 illustrates a more complete vision that fits the value chain to the elements of the project. Break-out discussion groups were configured to bring together specific teams on the project. The project progressed with five primary teams that discussed their research and advances at least monthly. These teams were 1) Metrics, 2) Nowcasting, 3) Numerical Weather Prediction, 4) Engineering, and 5) Management (including all team leads). This proved to be an effective way to manage the flow of the project. 
Alessandrini, S., L. Delle Monache, S. Sperati, and G. Cervone, 2015: An analog ensemble for short-term probabilistic solar power forecast. Appl. Energy, 157, 95-110, doi:10.1016/j.apenergy.2015.08.011.

Auligné, T., 2014a: Multivariate minimum residual method for cloud retrieval. Part I: Theoretical aspects and simulated observation experiments. Mon. Wea. Rev., 142, 4383-4398, doi:10.1175/MWR-D-13-00172.1.

Auligné, T., 2014b: Multivariate minimum residual method for cloud retrieval. Part II: Real observations experiments. Mon. Wea. Rev., 142, 4399-4415, doi:10.1175/MWR-D-13-00173.1.

Curtright, A. E., and J. Apt, 2008: The character of power output from utility-scale photovoltaic systems. Progress in Photovoltaics: Research and Applications, 16, 241-247, doi:10.1002/pip.786.

Davy, R. J., and A. Troccoli, 2012: Interannual variability of solar energy generation in Australia. Sol. Energy, 86, 3554-3560, doi:10.1016/j.solener.2011.12.004.

Delle Monache, L., T. Nipen, Y. Liu, G. Roux, and R. Stull, 2011: Kalman filter and analog schemes to postprocess numerical weather predictions. Mon. Wea. Rev., 139, 3554-3570, doi:10.1175/2011MWR3653.1.

Delle Monache, L., F. A. Eckel, D. L. Rife, B. Nagarajan, and K. Searight, 2013: Probabilistic weather prediction with an analog ensemble. Mon. Wea. Rev., 141, 3498-3516, doi:10.1175/MWR-D-12-00281.1.

Deng, A., N. L. Seaman, and J. S. Kain, 2003: A shallow-convection parameterization for mesoscale models. Part I: Submodel description and preliminary applications. J. Atmos. Sci., 60, 34-56, doi:10.1175/1520-0469(2003)060<0034:ASCPFM>2.0.CO;2.

Deng, A., B. Gaudet, J. Dudhia, and K. Alapaty, 2014: Implementation and evaluation of a new shallow convection scheme in WRF. $26^{\text {th }}$ Conf. on Weather Analysis and Forecasting/22 ${ }^{\text {nd }}$ Conf. on Numerical Weather Prediction, Atlanta, GA, Amer. Meteor. Soc., 12.5. [Available online at https://ams.confex.com/ams/94Annual/webprogram/Manuscript/Paper236925/12 5_22nd_NWP_Conf_Deng_ExtendedAbstract.pdf.]

Descombes, G., T. Auligné, H.-C. Lin, D. Xu, C. Schwartz, and F. Vandenberghe, 2014: Multisensor Advection Diffusion Nowcast (MADCast) for cloud analysis and short-term prediction. NCAR Tech. Note NCAR/TN-509+STR, 21 pp., doi:10.5065/D62V2D37.

Dubus, L., 2014: Weather and climate and the power sector: Needs, recent developments, and challenges, in Weather Matters for Energy (Troccoli, Dubus, and Haupt, Eds.), Springer, New York, doi:10.1007/978-1-4614-9221-4_18. 
Ela, E., V. Diakov, E. Ibanez, and M. Heaney, 2013: Impacts of variability and uncertainty in solar photovoltaic generation at multiple timescales. NREL Tech. Report NREL/TP-5500-58274, 41 pp. [Available online at http://www.nrel.gov/docs/fy13osti/58274.pdf.]

Gilbert, K. K., and Coauthors, 2016: The National Blend of Global Models, Version One. 23 ${ }^{r d}$ Conf. on Probability and Statistics in the Atmospheric Sciences, New Orleans, LA, Amer. Meteor. Soc., 1.3. [Available online at https://ams.confex.com/ams/96Annual/webprogram/Paper285973.html.]

Gueymard, C. A., and S. M. Wilcox, 2011: Assessment of spatial and temporal variability in the US solar resource from radiometric measurements and predictions from models using groundbased or satellite data. Sol. Energy, 85, 1068-1084, doi:10.1016/j.solener.2011.02.030.

Haupt, S. E., and B. Kosović, 2016: Variable generation power forecasting as a big data problem. IEEE Trans. Sustainable Energy, 8 (2), pp. 725-732. doi:10.1109/TSTE.2016.2604679.

Haupt, S. E., and Coauthors, 2016: The SunCast solar power forecasting system: The results of the Public-Private-Academic Partnership to Advance Solar Power Forecasting. NCAR Tech. Note NCAR/TN-526+STR, 307 pp., doi:10.5065/D6N58JR2.

Hinkelman, L. M., A. Heidinger, C. Molling, M. Sengupta, and A. Habte, 2013: Relating solar resource variability to cloud type, ASES 42nd National Solar Conference, Baltimore, MD.

Hinkelman, L. M., A. Heidinger, C. Molling, M. Sengupta, and A. Habte, 2014: Relating solar resource variability to satellite-retrieved cloud properties, AMS 5th Conference on Weather, Climate, and the New Energy Economy, Atlanta, GA.

Jensen, T., T. Fowler, B. Brown, J. Lazo, and S. E. Haupt, 2016: Metrics for evaluation of solar energy forecasts. NCAR Tech. Note NCAR/TN-527+STR, 67 pp., doi:10.5065/D6RX99GG.

Jiménez, P. A., and Coauthors, 2016a: WRF-Solar: Description and clear-sky assessment of an augmented NWP model for solar power prediction. Bull. Amer. Meteor. Soc., 97, 1249-1264, doi:10.1175/BAMS-D-14-00279.1.

Jiménez, P. A., S. Alessandrini, S. E. Haupt, A. Deng, B. Kosović, J. A. Lee, and L. Delle Monache, 2016b: The role of unresolved clouds on short-range global horizontal irradiance predictability. Mon. Wea. Rev., 144, 3099-3107, doi:10.1175/MWR-D-16-0104.1.

Kleissl, J. (Ed.), 2013: Solar Energy Forecasting and Resource Assessment. Academic Press. 462 pp. ISBN 9780123971777.

Kuhn, M., S. Weston, C. Keefer, and N. Coulter, 2012: Cubist models for regression. R Project Doc., 18 pp. [Available online at https://cran.rproject.org/web/packages/Cubist/vignettes/cubist.pdf.]

Lazo, J.K., 2017a: Economic Assessment of Hydro-Met Services and Products: A Value Chain Approach. Working paper. Societal Impacts Program, National Center for Atmospheric Research, Boulder CO. 
Lazo, J.K., K. Parks, S.E. Haupt, and T. Jensen. 2017b: Economic Value of Research to Improve Solar Power Forecasting. Working paper. National Center for Atmospheric Research. Boulder, $\mathrm{CO}$.

Lee, J. A., S. E. Haupt, P. A. Jiménez, M. A. Rogers, S. D. Miller, and T. C. McCandless, 2017: Solar irradiance nowcasting case studies near Sacramento. J. Appl. Meteor. Climatol., 56, 85108. doi:10.1175/JAMC-D-16-0183.1.

Lew, D., G. Brinkman, E. Ibanez, M. Hummon, B.-M. Hodge, and M. Heaney, 2012: Sub-hourly impacts of high solar penetrations in the western United States. $2^{\text {nd }}$ Annual International Workshop on Integration of Solar Power into Power into Power Systems Conf., Lisbon, Portugal, 12-13 Nov 2012. [Available online at http://www.nrel.gov/docs/fy12osti56171.pdf.]

Lorenz, E., J. Kuhnert, and D. Heinemann, 2014: Overview of irradiance and photovoltaic power prediction, in Weather Matters for Energy (Troccoli, Dubus, and Haupt, Eds.). Springer, New York, doi:10.1007/978-1-4614-9221-4_21.

Mahoney, W. P., and Coauthors, 2012: A wind power forecasting system to optimize grid integration. IEEE Trans. Sustainable Energy, 3, 670-682, doi:10.1175/2011BAMS3033.1.

Martinez-Anido, C. B., B. Botor, A. R. Florita, C. Draxl, S. Lu, H. F. Hamann, and B.-M. Hodge, 2016: The value of day-ahead solar power forecasting improvement. Sol. Energy, 129, 192-203, doi:10.1016/j.solener.2016.01.049.

McCandless, T. C., S. E. Haupt, and G. S. Young, 2015: A model tree approach to forecasting solar irradiance variability. Sol. Energy, 120, 514-524, doi:10.1016/j.solener.2015.07.020.

McCandless, T. C., S. E. Haupt, and G. S. Young, 2016a: A regime-dependent artificial neural network technique for short-range solar irradiance forecasting. Renewable Energy, 89, 351-359, doi:10.1016/j.renene.2015.12.030.

McCandless, T. C., G. S. Young, S. E. Haupt, and L. M. Hinkelman, 2016b: Regime-dependent short-range solar irradiance forecasting. J. Appl. Meteor. Climatol., 55, 1599-1613, doi:10.1175/JAMC-D-15-0354.1.

Miller, S. D., M. A. Rogers, A. K. Heidinger, I. Laszlo, and M. Sengupta, 2012: Cloud advection schemes for short-term satellite-based insolation forecasts. Proc. World Renewable Energy Forum, Denver, CO, Amer. Sol. Energy Soc., 1963-1967. [Available online at https://ases.conference-services.net/resources/252/2859/pdf/SOLAR2012_0385_full paper.pdf.]

Myers, W., G. Wiener, S. Linden, and S. E. Haupt, 2011: A consensus forecasting approach for improved turbine hub height wind speed predictions, in Proc. WindPower 2011, Anaheim, CA, May 24, 2011.

Peng, Z., D. Yu, D. Huang, J. Heiser, S. Yoo, and P. Kalb, 2015: 3D cloud detection and tracking system for solar forecast using multiple sky imagers. Sol. Energy, 118, 496-519, doi:10.1016/j.solener.2015.05.037. 
Perez, R., and Coauthors, 2013: Comparison of numerical weather prediction solar irradiance forecasts in the US, Canada, and Europe. Sol. Energy, 94, 305-326, doi:10.1016/j.solener.2013.05.005.

Quinlan, J. R., 1992: Learning with continuous classes. Proc. AI '92, A. Adams and L. Sterling, Eds., World Scientific, 343-348. [Available online at http://sci2s.ugr.es/keel/pdf/algorithm/congreso/1992-Quinlan-AI.pdf.]

Rogers, M. A., S. D. Miller, J. M. Haynes, A. Heidinger, S. E. Haupt, and M. Sengupta, 2015: Improvements in satellite-derived short-term insolation forecasting: Statistical comparisons, challenges for advection-based forecasts, and new techniques. Sixth Conf. on Weather, Climate, and the New Energy Economy, Phoenix, AZ, Amer. Meteor. Soc., 6.4. [Available online at https://ams.confex.com/ams/95Annual/webprogram/Paper268850.html.]

Ruiz-Arias, J. A., H. Alsamanra, J. Tovar-Pescador, and D. Pozo-Vázquez, 2010: Proposal of a regressive model for the hourly diffuse solar radiation under all sky conditions. Energy Convers. Manage., 51, 881-893, doi:10.1016/j.enconman.2009.11.024.

Ruiz-Arias, J. A., J. Dudhia, F. J. Santos-Alamillos, and D. Pozo-Vázquez, 2013: Surface clearsky shortwave radiative closure intercomparisons in the Weather Research and Forecasting model. J. Geophys. Res. Atmos., 118, 9901-9913, doi:10.1002/jgrd.50778.

Ruiz-Arias, J. A., J. Dudhia, and C. A. Gueymard, 2014: A simple parameterization of the shortwave aerosol optical properties for surface direct and diffuse irradiances assessment in a numerical weather model. Geosci. Model Dev., 7, 1159-1174, doi:10.5194/gmd-7-1159-2014.

Schroedter-Homscheidt, M., A. Oumbe, A. Benedetti, and J.-J. Morcrette, 2013: Aerosols for concentrating solar electricity production forecasts. Bull. Amer. Meteor. Soc., 94, 903-914, doi:10.1175/BAMS-D-11-00259.1.

Skamarock, W. C., and Coauthors, 2008: A description of the Advanced Research WRF version 3. NCAR Tech. Note NCAR/TN-475+STR, 113 pp., doi:10.5065/D68S4MVH.

Thompson, G., and T. Eidhammer, 2014: A study of aerosol impacts on clouds and precipitation development in a large winter cyclone. J. Atmos. Sci., 71, 3636-3658, doi:10.1175/JAS-D-13$\underline{0305.1 .}$

Troccoli, A., L. Dubus, and S. E. Haupt (Eds.), 2014: Weather Matters for Energy. Springer, New York. 528 pp., doi:10.1007/978-1-4614-9221-4.

Tuohy, A., and Coauthors, 2015: Solar forecasting: Methods, challenges, and performance. IEEE Power Energy Mag., 13, 50-59, doi:10.1109/MPE.2015.2461351.

Utsler, J., 2014: The Watt-Sun is poised to improve weather forecasting for solar energy, IBM Systems Magazine, http://www.ibmsystemsmag.com/power/trends/ibmresearch/watt-sun/.

Wilks, D. S., 2011: Statistical methods in the atmospheric sciences, $3^{\text {nd }}$ Ed., Academic Press, 676 pp. 
701 Woodhouse, M. R. Jones-Albertus, D. Feldman R. Fu, K. Horowitz, D. Chung, D. Jordan, and S. 702 Kurtz, et al., 2016: On the path to SunShot: The role of advancements in solar photovoltaic

703 efficiency, reliability, and costs, NREL/TP-6A20-65872, 43 pp.

704 Xie, Y., M. Sengupta, and J. Dudhia, 2016: A Fast All-sky Radiation Model for Solar 705 applications (FARMS): Algorithm and performance evaluation. Sol. Energy, 135, 435-445, 706 doi:10.1016/j.solener.2016.06.003.

707 Zhang, J., A. Florita, B.-M. Hodge, Si. Lu, H.F. Hamann, V. Banunarayanan, and A. M. Brockway, 708 2015: A suite of metrics for assessing the performance of solar power forecasting, Solar Energy, 709 111, pp. 157-175, doi: 10.1016/j.solener.2014.10.016.

710

711 
714 Table 1. Consensus of metrics to be exercised in evaluating solar power forecasting systems.

\begin{tabular}{|c|c|c|c|}
\hline & Model-Reference Comparison & \multicolumn{2}{|c|}{ Utility Planning/Operations Support } \\
\hline & Statistical Information & Statistical & Economic/Value \\
\hline Base & $\begin{array}{l}\text { BC1: Distribution of Forecast Errors } \\
\text { BC2: Mean Absolute Error } \\
\text { BC3: RMSE } \\
\text { BC4: Standard Deviation/Variance } \\
\text { BC5: Pearson's Correlation } \\
\text { Coefficient } \\
\text { BC6: Categorial Statistics for Event } \\
\text { BC7: Frequency of Superior } \\
\text { Performance }\end{array}$ & $\begin{array}{l}\text { BP1: Mean Bias Error } \\
\text { BP2: Skewness } \\
\text { BP3: Kurtosis } \\
\text { BP4: } 99^{\text {th }} \text { Percentile }\end{array}$ & $\begin{array}{l}\text { BV1: Operating } \\
\text { Reserves Analysis } \\
\text { BV2: Electricity } \\
\text { Production Cost } \\
\text { Analysis }\end{array}$ \\
\hline Enhanced & $\begin{array}{l}\text { EC1: Kolmogorov-Smirnov Test } \\
\text { Integral } \\
\text { EC2: OVER Metric } \\
\text { EC3: Renyi Entropy } \\
\text { EC4: Paired Test for Mean and } \\
\text { Variance } \\
\text { EC5: Performance Diagram for } \\
\text { Continuous Statistics }\end{array}$ & $\begin{array}{l}\text { EP1: Probability } \\
\text { Interval Forecast } \\
\text { Evaluation } \\
\text { EP2: Brier Score } \\
\text { EP3: Receiver Operator } \\
\text { Characteristic Curve } \\
\text { and Area } \\
\text { EP4: Reliability } \\
\text { Diagram }\end{array}$ & $\begin{array}{l}\text { EV1: Electricity Load } \\
\text { Payments Analysis } \\
\text { EV2: Solar Generation } \\
\text { Curtailment } \\
\text { EV3: Power Trading } \\
\text { Impact } \\
\text { P1: Load Forecast } \\
\text { Improvement } \\
\text { P2: Storage } \\
\text { Optimization }\end{array}$ \\
\hline
\end{tabular}


Figure Headings:

Figure 1. Value chain implementing a weather decision support system for solar power. At the bottom are the components of the NCAR team's system that build toward providing an economic impact of this system.

Figure 2. Sun4Cast forecasting system predicts across scales. The fuzzy ovals roughly indicate the time scales of each component's forecast. Each component is discussed in the text.

Figure 3: Diagram showing the WRF-Solar augmentations that now include specific interactions between the radiation, clouds, and aerosols

Figure 4. MAE in $\mathrm{W} \mathrm{m}^{-2}$ for Day-Ahead forecasts from DICast components and Sun4Cast system at all partner locations and all sky conditions.

Figure 5. MAE in $\mathrm{W} \mathrm{m}^{-2}$ for all Nowcast components aggregated over all partners and all sky conditions (upper left), clear (upper right), partly cloudy (lower left), and cloudy (lower right) sky conditions. 


\section{Value Chain: \\ What is the value of solar power forecasting?}
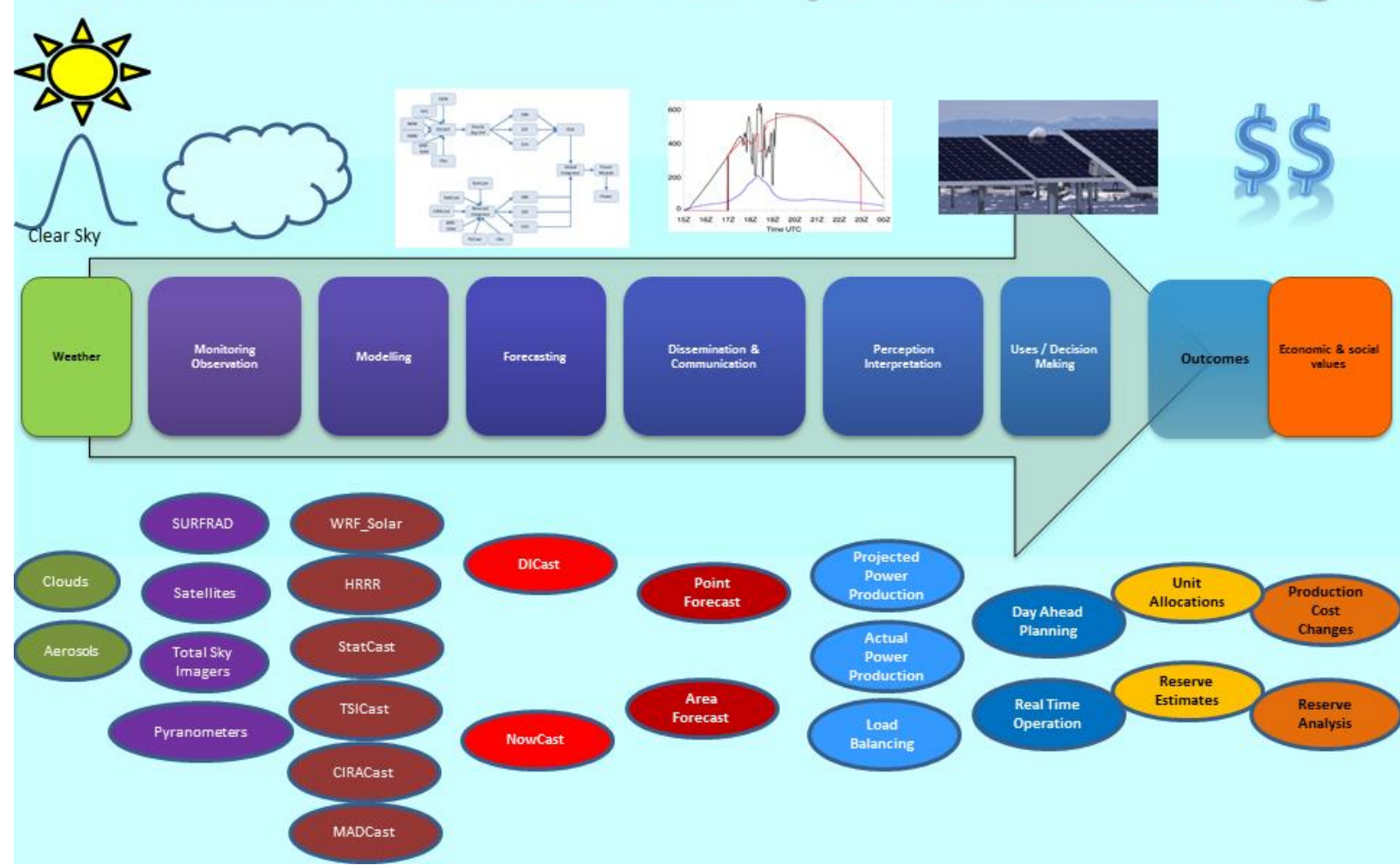

Figure 1. Value chain implementing a weather decision support system for solar power. At the bottom are the components of the NCAR team's system that build toward providing an economic impact of this system. 


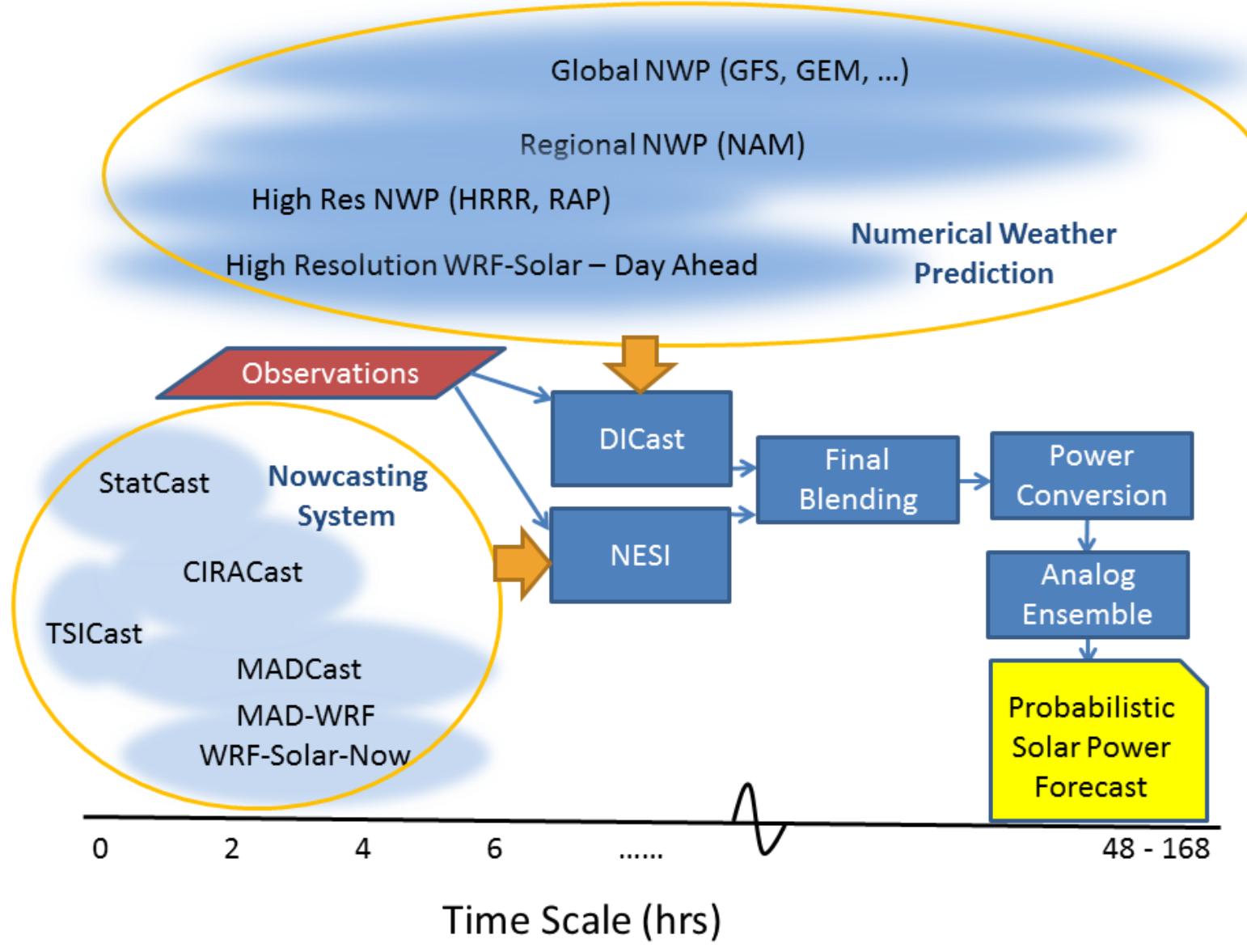

728 Figure 2. Sun4Cast forecasting system predicts across scales. The fuzzy ovals roughly indicate 729 the time scales of each component's forecast. Each component is discussed in the text. 


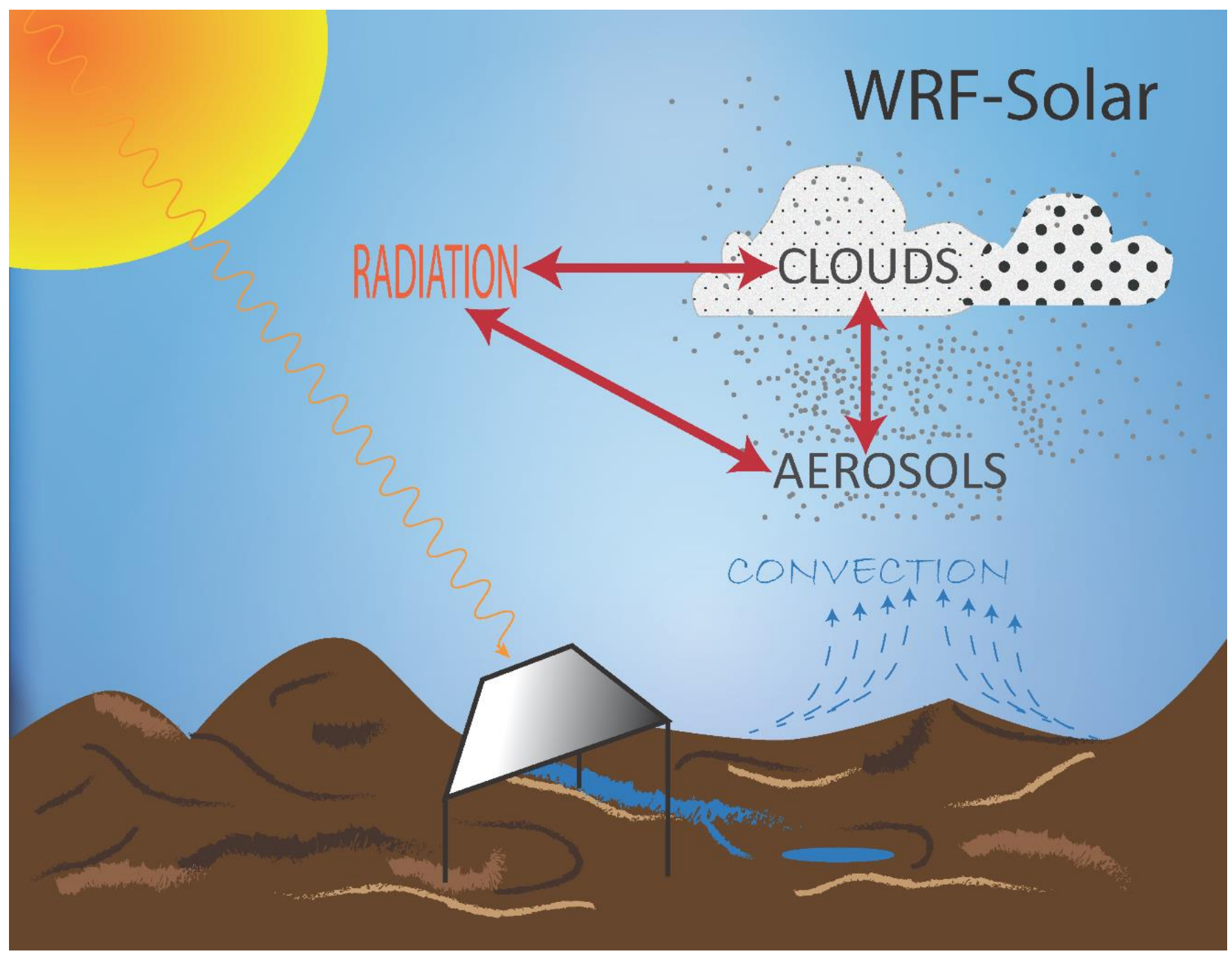
between the radiation, clouds, and aerosols. 
Sun4Cast Components - Day Ahead Performance

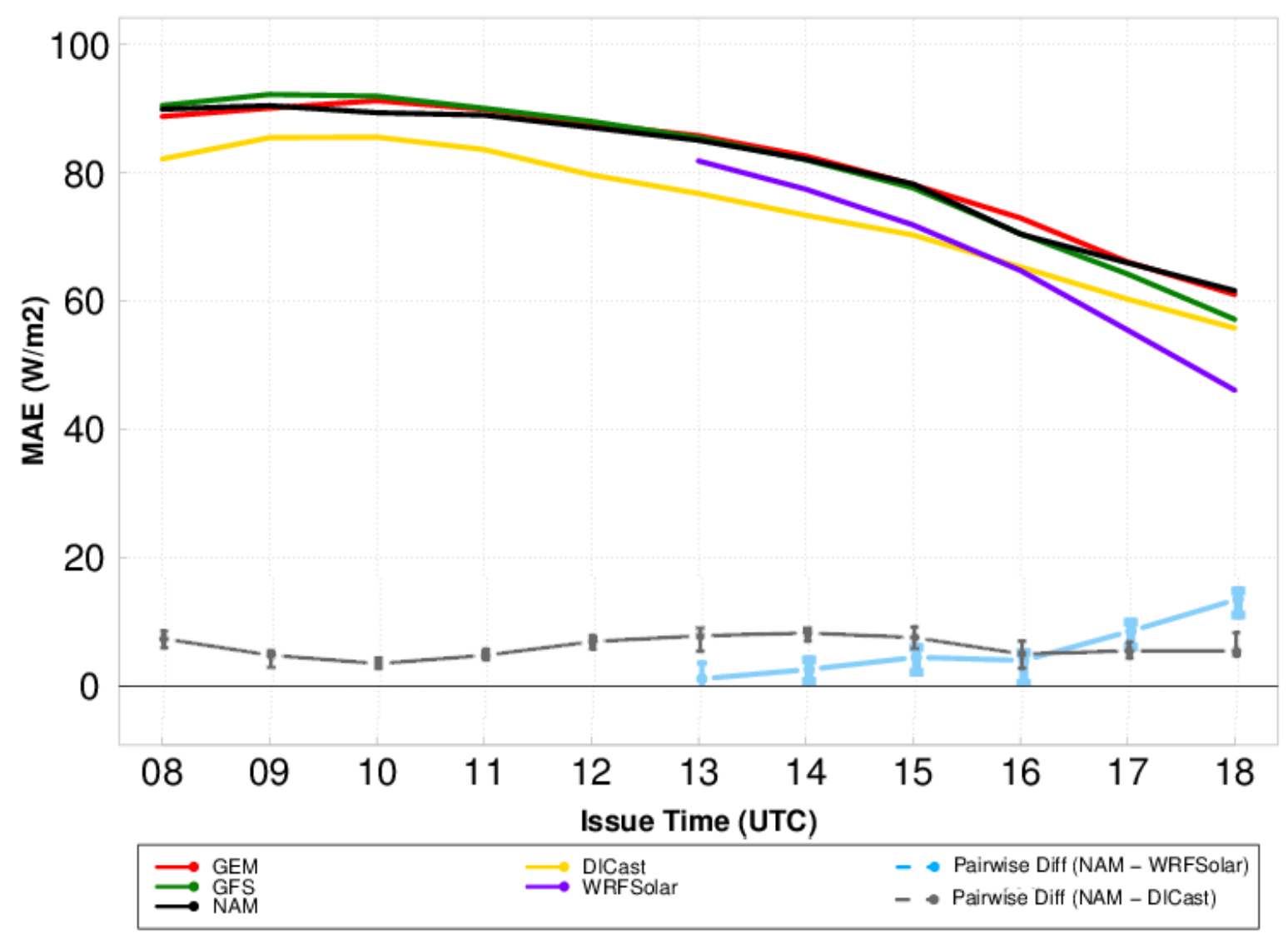

736

737

738

739

740

Figure 4. MAE in $\mathrm{W} \mathrm{m}^{-2}$ for day-ahead forecasts from DICast components and Sun4Cast system at all partner locations and all sky conditions. Pairwise differences between NAM \& DICast (gray) and NAM and WRF-Solar (blue) are shown with bootstrapped confidence intervals using 95\% significance. Places where the interval does not encompass 0 are statistically significant. 

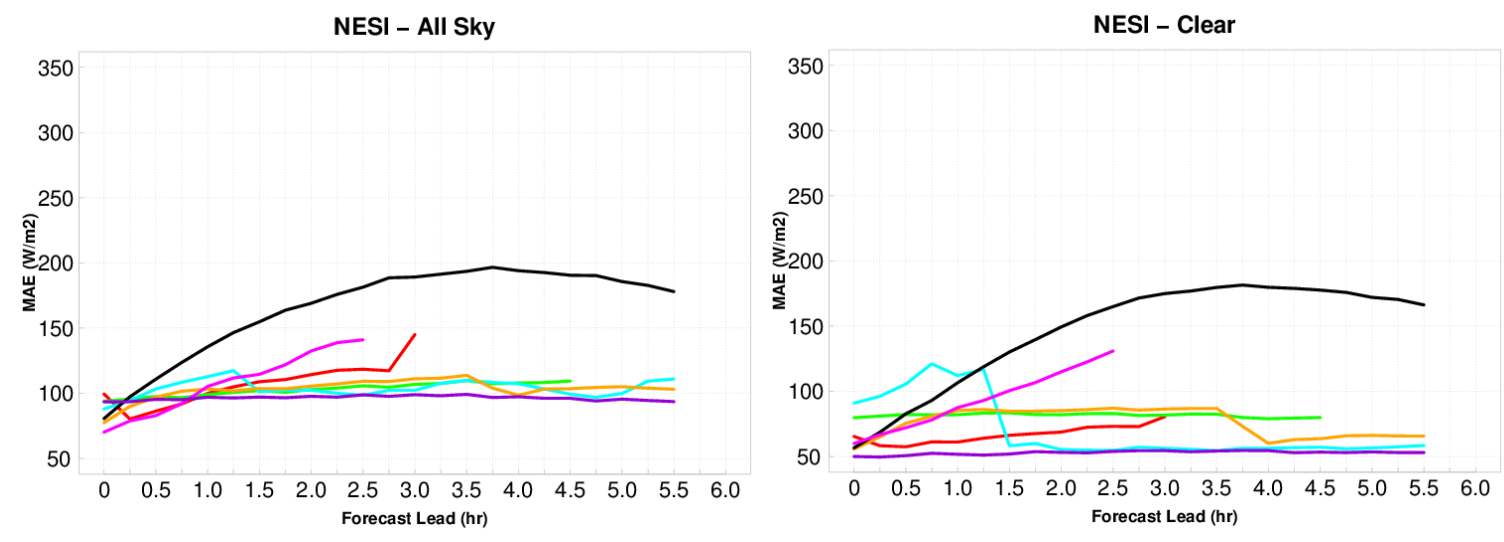

742

NESI - Partly Cloudy

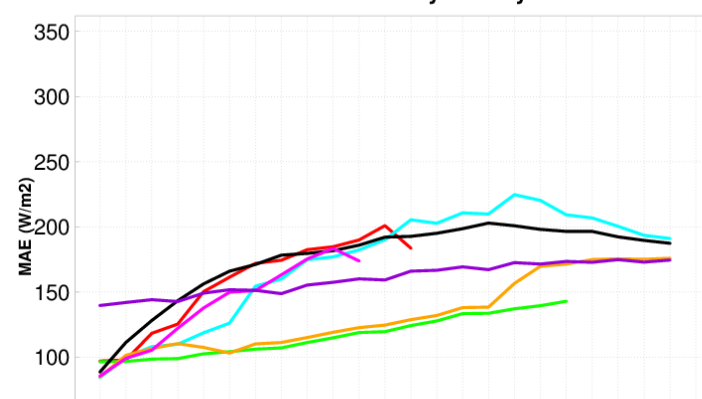

50

$\begin{array}{lllllllllllll}0 & 0.5 & 1.0 & 1.5 & 2.0 & 2.5 & 3.0 & 3.5 & 4.0 & 4.5 & 5.0 & 5.5 & 6.0\end{array}$

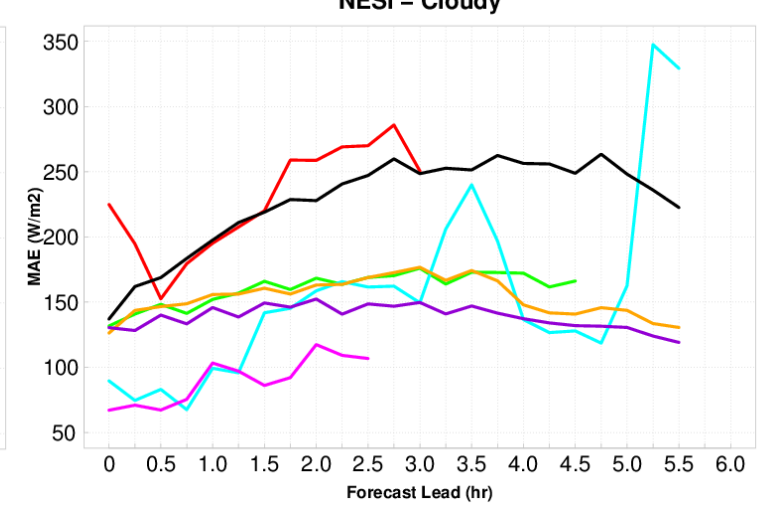

$\longrightarrow$ CIRACast $\quad \longrightarrow$ MAD_WRF $\longrightarrow$ NowCast $\quad \longrightarrow$ StatCast_cubist $\longrightarrow$ WRFSolarNow

744

745

746

747

748 


\title{
Building the Sun4Cast System: Improvements in Solar Power Forecasting
}

\author{
Sue Ellen Haupt ${ }^{1}$, Branko Kosović ${ }^{1}$, Tara Jensen ${ }^{1}$, Jeffrey K. Lazo ${ }^{1}$, Jared A. Lee ${ }^{1}$, \\ Pedro A. Jiménez ${ }^{1}$, James Cowie ${ }^{1}$, Gerry Wiener ${ }^{1}$, Tyler C. McCandless ${ }^{1,6}$, \\ Matthew Rogers ${ }^{2}$, Steven Miller ${ }^{2}$, Manajit Sangupta ${ }^{3}$, Yu Xie ${ }^{3}$, Laura Hinkelman ${ }^{4}$, \\ Paul Kalb ${ }^{5}$, John Heiser ${ }^{5}$
}

\section{Response to Reviewer's Comments}

The authors thank the reviewers for their careful reading of our manuscript and thoughtful comments. We believe that responding to those comments has strengthened the paper. Each reviewer's comments (in blue) and our responses are detailed below.

Reviewer 1: We thank the reviewer for the complimentary comments. Some specific responses include:

Page 9 (line 202) If it's easy to include which two aerosol species are allowed, please consider doing so. I found myself wondering about this, which is a minor distraction.

We have clarified (Page 9, lines 201-203) that “...only two general aerosol species are allowed, specifically the nonhygroscopic ice-nucleating aerosols which are dust particles and the hygroscopic aerosols including sea-salts, organic matter, and sulfates.".

Page 13 (lines 288-289) If it is easy to add a brief explanation as to how use of a Cubist regression tree model implicitly accounts for the specifics of solar panel installation, mitigating meta-date problems please do so. I found myself wondering about this, which is a minor distraction.

We have added a brief explanation that Cubist trains "the power output directly to the observed input solar irradiance," which resolves problems with inaccurate metadata (lines 283-285).

Page 13 (lines 290-295) If it is easy to add brief explanation about the analog ensemble technique, please do so. Something like the following might suffice: The AnEn method uses historical pairs of NWP forecasts and observations of solar power production. The method matches a current forecast to an historical forecast and its associated power production. If it's easy, please add a description of how the AnEn technique quantifies the uncertainty in the current forecast.

We have added a brief explanation of the AnEn as requested (lines 298-303): "The last step in the forecast process applies the analog ensemble technique (AnEn; Delle Monache et al. 2011, 2013; Alessandrini et al. 2015). The AnEn searches the database for past forecasts most similar to the current forecast. It then forms a probability density function (pdf) of the observations that correspond to those historical forecasts. The mean of this pdf becomes the improved forecast and its spread quantifies the uncertainty." 
Topographical Errors and Style/Grammar Suggestions: These errors have all been corrected. Thank you for finding them.

Reviewer 2: Thank you for the recommendation of acceptance. The minor errors that you mention have been corrected.

\section{Reviewer 3:}

It appears that although Sun4Cast has integrated a number of forecasting technologies and blended a number of forecast systems, the output from DIcast and NowCast are still point forecasts. Firstly I am wondering how such kind of point forecast is obtained. The authors keep using the word "blended" in various situations without any clarification. Similarly "a consensus forecasting approach" is mentioned (Line151-153), it is again unclear how multiple input forecasts are integrated.

The reviewer is correct that both DICast and NESI provide point forecasts. For the NESI models, each is configured specifically for a specific site. For the NWP models that go into DICast, the model grid is interpolated to a point (the site of the solar farm or observation point) than corrected with information from the observations. The blending is basically weighting the average based on past performance of each input model. This is now described in more detail in the revised manuscript (p. 8, lines 150-153): "Both NESI and DICast apply a consensus forecasting approach, meaning that they blend and optimize multiple models to provide a better forecast than any of the models would produce alone."

We have also clarified the meaning of "a consensus forecasting approach," which we take to mean as a blending and optimization using multiple models to provide a better forecast than any of the single models alone would produce (p. 8, lines 152-153)

Secondly the authors did not provide any uncertainties quantification that attaches to such point forecasts. Have the authors considered providing predictive forecast distributions?

Yes, the forecasts do quantify the uncertainty using the Analog Ensemble approach, as described on p. 13, lines 298-306. The full project report (Haupt et al. 2016) provides examples of the probabilistic forecasts, but those were not explicitly included here to conserve space.

Line 290-295, analog ensemble technique is applied to provide "probabilistic information to quantify uncertainty of the forecast", it appears to me that the AnEn is applied based upon point solar forecasts to provide ensemble power forecasts, the claims that this project "effectively quantified the uncertainty in the solar forecasts..." and Line 364-365 "uncertainty quantification for GHI forecasts." are incorrect.

The Analog Ensemble technique does quantify the uncertainty in the power produced. A few more sentences have been added to the manuscript to clarify how it does this (p. 13, lines 299304). We also now specify that the uncertainty is in the solar power forecasts (line 305). 
ii) Line 169-171, it is noted from former intercomparison that "ECMWF global model significantly outperforms the GFS-driven WRF model...". A number augmentations are listed and discussed in Page 9-10. I can't help asking after conducting all these augmentations, quantitatively how much improvement is made? Does the upgraded WRF model now outperform or become comparable to ECMWF model?

The ECMWF model is discussed in terms of what prior authors have found using a standard version of WRF. NCAR did not purchase ECMWF forecasts for this project, so no specific comparisons of WRF-Solar to it were possible. Here, our reference forecast was the U.S. North American Model (NAM) and we compare both WRF-Solar and DICast to the NAM (see Figure 4). Both WRF-Solar and DICast outperform the NAM forecast.

The authors have explained why those augmentations are made. Even though the improvement is expected, it is not necessarily the case that making all the augmentations together will improve the forecast. Even it does, some of the augmentations might be irrelevant to the overall improvement. It would be better if the authors can quantify the contribution to the overall improvement for each augmentation.

Detailed comparisons of each of those augmentations are beyond the scope of this current overview paper. Those comparisons appear in the prior publications that described these augmentations more specifically and detailed the verification process to assure that the augmentations each provided a positive benefit (Ruiz-Arias et al. 2014; Jimenez et al. 2016a, b; Xie et al. 2016; Haupt et al. 2016; Lee et al. 2017).

iii) Line 403-404 the authors claim the Sun4Cast system "has been thoroughly evaluated". Line 435-437, "carefully chosen metrics allow ...".

I agree carefully chosen metrics is important, however, it is unclear to me it is done so in this project. There are a large number metrics listed in Table 1. Why the authors prefer using MAE to present the evaluation results in Figure 4 and 5? And why switch to RMSE when evaluate power forecast Line 366-370

The evaluations presented in Figure 4 and 5 are based on finite forecast samples, some sort of uncertainties bars are required to demonstrate whether the differences in MAE are significant.

The comparisons in this paper are a small sample of the ones accomplished and presented in the 307-page project report referenced in the manuscript (Haupt et al. 2016). It is beyond the scope of this overview paper to go into all of the details of the verifications of each of the input models. Our goal here is merely to provide a sampling of results and summarize the primary findings. However, we have updated Figure 4 to include pairwise differences between one operational model (NAM) and the DICast system and WRF-Solar component. The manuscript now explicitly states "Statistical analysis through pairwise differences and bootstrapped confidence intervals indicates that these results are statistically significant at the $95 \%$ level for all issue times when NAM is compared to DICast and all but the first lead time when NAM is compared to WRF-Solar . Figure 5-13 in Haupt et al. (2016), also indicates statistically significant results at all lead times." (p. 14, lines 328-332. For more details, the reviewer and readers are referred to the report, available on-line at http://opensky.ucar.edu/islandora/object/technotes:539. There the 
statistical significance of the results are also provided, which is summarized quite briefly on p. 14 of the manuscript.

The results in Figure 5 are odd as the performances of some models fluctuate when lead time increases. Normally one would expect the forecast performance degrades as lead time increases. Please explain why it is not the case here.

In Figure 5, the forecast errors do fluctuate according to lead time, but most of them tend to increase with lead time, as expected. The ones that perhaps fluctuate the most are for cloudy conditions. For such conditions, forecasts can be quite difficult, and averaged over multiple sites and over a large time, it is not unexpected that fluctuations would occur. Also note that the models that tend to reduce errors with lead time are the blended models like MAD-WRF and the NESI nowcast blending. These forecasts switch from the performance of one model to another, so a discontinuity is expected. This is now pointed out in the revised manuscript (p. 14, lines 345-346). Also, there could be a small tendency towards smaller errors at the end of the forecast period, which is likely associated with the diurnal cycle.

For Figure 4, note that the $\mathrm{x}$-axis is not lead time, but rather issue time. In terms of issue time, morning forecasts may be more difficult due to the unavailability of visible satellite data in the morning to assimilate into the models. In addition, combining early-morning forecasts with midday forecasts can lead to some odd aggregate behavior in the average raw MAE as a function of lead time.

iv) In "Economic Valuation" section, the authors cited various research work, suggest solar power forecasting improvement would reduce operational electricity generation costs. Line 390395, "50\% improvement... will save their customers \$819,200 in 2024... an annual expected savings for this 50\% forecast error reduction ranges from $\$ 11$ in 2015 to ..."

How is $50 \%$ improvement quantified? Using RMSE? Note these expected savings for "50\% forecast error reduction" would depend on the forecast error of the former forecast system, and the relationship between forecast improvement and expected saving might not be linear. The quantification (or at lease estimation) of the expected savings due to the use of Sun4Cast system would help demonstrate the potential economic gain from this project.

The 50\% is in terms of MAE and is derived from Figure 5-5 of Haupt et al. (2016) and stated in the text (" The improvement in performance at Xcel between April 2015 and March 2016 represents a 45-48\% improvement within the timeframe of the project." - p. 206 of that document, p. 17). It compares our Sun4Cast system as originally set up (expected to compare well with typical, pre-project predictions) and after having spent some time improving the system over the course of the project. This is now stated more clearly in the manuscript on p. 17, lines 406-407. We agree that there is a non-linear relationship between forecast improvement and cost savings. We also agree that estimating expected savings is helpful to demonstrate the economic gain from the project. That is the reason that we present this information in the paper, and in more detail in the above-referenced report, as well as in a forthcoming manuscript. 
1) Line 40, "provides recommendations for best-practice solar forecasting" I do find most recommendations are useful, but I would not use the word "best"

Merriam-Webster defines "best practice" to mean "a procedure that has been shown by research and experience to produce optimal results and that is established or proposed as a standard suitable for widespread adoption." https://www.merriamwebster.com/dictionary/best\%20practice. Because we accomplished extensive verification on multiple forecasting methods, we believe that we are in a position to synthesize this information into a series of "best practices" recommendations, which are provided as part of this paper. We now add quotation marks around the first use of the term "best practices" on p. 4 , line 40.

2) Line 76 "accurate solar forecasts", is the best available solar forecasts accurate?

Level of accuracy is a judgement call, of course. Here we use the word "accurate" to distinguish from the first very cursory attempts at solar power forecasting at the beginning of grid integration over a decade ago. Because the paper is about improving the quality of solar power forecasts, we believe that the qualifier is appropriate in this context.

3) Line 92, how to qualify "excellent aerosol prediction"? I would phrase this alternatively, for example, the need for the improvement of aerosol prediction...

This passage refers to the work of Schroedter-Homscheidt et al. (2013) in a prior BAMS article. That paper pointed out the importance of having very high quality forecasts of aerosols as a necessary condition to correctly forecast Direct Normal Irradiance (DNI) for concentrated solar applications. However, we have taken your point and made the suggested change.

4) Line 116, "A second set of stakeholders", what is the first set? The end users?

As stated in the paragraph on p. 6, bottom, yes, the first set of stakeholders does include the end users at the electric utilities and system operators.

5) Line 173, "forecast models are not optimal", I don't believe an optimal model exists, even it does, I don't think ECMWF model is optimal either.

We do not mean to imply that ECMWF is optimal, but rather to distinguish it as perhaps superior to the GFS-based models for solar irradiance prediction. To that end, we have changed the wording on p. 8, line 173 to "do not perform as well."

6) Line $239, " 15-50 \% "$ of what?

As stated in that line, as compared to smart persistence. We have added now that it is compared in terms of MAE.

7) Line 261-262, please clarify what does it mean by "effective", smaller MAE? 
We have added an example here (Page 12, lines 263-266) to clarify our meaning: "For instance, the satellite-based method, CIRACast, provides the best initial state during partly cloudy conditions, although that may not carry through to clear or fully cloudy conditions. It does, however, provide value for forecasting short-range ramps due to changing cloud cover (Figure 58 of Haupt et al. 2016)."

\section{8) Line 271: please clarify "smartly blend"}

We have added a phrase here (Page 12, lines 270-271) to clarify our meaning: "It is also critical to engineer a system that smoothly handles data input and output and effectively blends the results of each of the components.".

9) Line 374-375, "computed Brier skill score...was 0.55", why "0.55" suggests improvement?

This is actually a Brier Skill Score, which compares forecasts to a baseline and normalizes. Thus, a Brier Skill Score of 0.55 can be interpreted as a 55\% improvement over the baseline forecast, which in this case compares the $50 \%$ probability interval of the AnEn to the Sun4Cast prediction.

10) Line 409-411, according Figure 4. and 5., "blended models/systems invariably significantly better than... single model" is not true.

The reviewer makes a good point. We should qualify this statement as true on average, over all lead times. This has been done.

11) Line 429-430, Please justify AnEn produces "a probabilistic prediction that is well calibrated"

This statement is justified based on our assessments of AnEn above (p. 16, lines 387-390). We have added a few more statements to enlarge the discussion of assessment beyond the $50 \%$ probability of exceedance provided previously: "Improvements in power forecasts are similar to those reported for GHI forecasts with a median improvement of $17 \%$ in RMSE.

Probabilistic forecasts were also computed for 10, 25, 50, 75, and 90\% exceedance of power capacity. A marked improvement was obvious in terms of Brier Skill Score (Wilks 2011) for probabilities of an exceedance of $50 \%$ of capacity (Haupt et al. 2016). The computed Brier Skill Score across all lead times was 0.55 (Figure 5-23 of Haupt et al. 2016).”

12) Line 449-453, Chaos limits model predictability, so does the model error. Has such "theoretical limit on ..timeframe" been estimated?

"Forecasts from Sun4Cast are provided every $15 \mathrm{~min}$, extend to $72 \mathrm{~h}$, and can be provided as far out as 168 h. "(Line 160)? Are "72h", "168h" related to such "theoretical limit"?

The team actually had hoped to quantify those limits of predictability, but DOE did not wish their funds to be spent on that endeavor, so it was never completed. No, there is no intentional 
relationship between the forecast lengths and the limits of predictability. Those forecast lengths were instead set according to the needs of the end users.

Reviewer 4: Thank you for complimentary comments. The minor errors that you noted have been corrected. 
Figure 1

Click here to access/download

\section{Non-Rendered Figure Figure1.tif}


Figure 2

Click here to access/download

\section{Non-Rendered Figure Figure2.tif}


Figure 3

Click here to access/download

\section{Non-Rendered Figure Figure3.tif}


Figure 4

Click here to access/download

\section{Non-Rendered Figure Figure4.tif}


Figure 5

Click here to access/download

\section{Non-Rendered Figure Figure5.tif}

